Historia

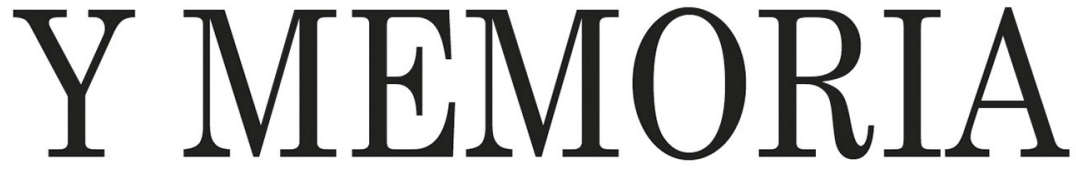

ISSN: 2027-5137 Julio - Diciembre, Año 2016 - Tunja, Colombia

La libertad de imprenta en la América española (ensayo de historia comparada sobre la opinión pública moderna)

Gilberto Loaiza Cano Páginas: 47 - 84 DOI: http://dx.doi.org/10.19053/20275137.5200

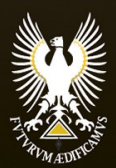




\title{
La libertad de imprenta en la América española (ensayo de historia comparada sobre la opinión pública moderna)*
}

\author{
Gilberto Loaiza Cano ${ }^{1}$ \\ Universidad del Valle - Colombia
}

Recepción: 27/10/2015

Evaluación: 20/01/2016

Aprobación: 05/04/2016

Artículo de Investigación e Innovación.

DOI: http://dx.doi.org/10.19053/20275137.5200

\section{Resumen}

Este ensayo pretende mostrar las diferencias y semejanzas en el proceso de instauración de la libertad de imprenta en varios lugares de la América española. El análisis estará concentrado en los decenios 1810 a 1830, e incluye lo sucedido en Nueva España, Nueva Granada, Río de la Plata y Chile, principalmente.

Palabras clave: Libertad de imprenta, Censura, Opinión pública, Prensa.

\footnotetext{
* El presente artículo hace parte de la investigación del año sabático del autor titulada «El lenguaje político de la república» (2014).

1 Profesor titular del departamento de Historia, Universidad del Valle. Doctor en Sociología de la Universidad París III-Iheal; autor de dos estudios biográficos: Luis Tejada y la lucha por una nueva cultura (1995), Manuel Ancízar y su época (2004), Sociabilidad, religión y política en la definición de la nación (2011), Poder letrado (2014). Miembro del grupo de investigación Nación-Cultura-Memoria, responsable de la línea historia intelectual de Colombia, siglos XIX y XX. En la actualidad es jefe del departamento de Historia. Correo electrónico: loaizacanogilberto@hotmail.com
} 


\title{
Freedom of Publication in Spanish America (an Essay on the Comparative History of Modern Public Opinion)
}

\begin{abstract}
This essay attempts to demostrate differences and similitudes in the process of establishing freedom of publication in several locations of Spanish America. This analysis will concentrate on the decades between 1810 and 1830 and will mainly include the events occurred in New Spain, New Granada, Río de la Plata and Chile.
\end{abstract}

Key words: Freedom of publication, censorship, public opinion, press.

\section{La liberté de presse dans l'Amérique espagnole (essai d'histoire comparée de l'opinion publique moderne)}

\section{Résumé}

L'objectif de cet essai est de montrer les différences et les ressemblances dans le processus d'instauration de la liberté de presse dans plusieurs lieux de l'Amérique espagnole. L'analyse portera sur les décennies de 1810 à 1830, et les territoires de la Nouvelle Espagne, la Nouvelle-Grenade, le Río de la Plata et le Chili, principalement.

Mots-clés: Liberté de presse, censure, opinion publique, presse.

\section{Introducción}

Varios historiadores coinciden en considerar los últimos decenios del siglo XVIII y los primeros del siglo siguiente como un periodo de tránsito en que un primer liberalismo se mezcló con los principios intelectuales y morales de la Ilustración y con los remanentes de una sociedad que aún no se regía por 
valores inherentes al individualismo. Dicho de otro modo, un orden jurídico nuevo y proclive a la extensión de libertades individuales contrastó por algún tiempo con una sociedad que veía todavía con recelo la emergencia de una categoría inquietante que empezaba a llamarse "opinión pública". Ese tiempo conoció tensiones entre quienes proclamaron y quisieron poner en práctica la libertad de imprenta y aquellos que estaban acostumbrados a ciertas restricciones en la expresión con tal de evitar la perturbación de "la tranquilidad pública". La aparición de periódicos e incluso impresos de factura más modesta en que los individuos difundían sus opiniones políticas fue una novedad difícil de admitir para una comunidad letrada acostumbrada a ver en los periódicos un instrumento de difusión de noticias moral y científicamente útiles, de curiosidades, de recetas de urbanidad, de leyes que pretendían contribuir a la felicidad general. De hecho, los primeros gobiernos prefirieron promover gacetas oficiales que garantizaran un necesario y rápido consenso y, al mismo tiempo, intentaron restringir e incluso prohibir la existencia de periódicos redactados por individuos interesados en la polémica política ${ }^{2}$.

En definitiva, hubo una etapa desapacible en que se enfrentaron aquellos que comenzaban a apelar al naciente y aparentemente imparcial "tribunal de la opinión pública", que preferían someterse a la aceptación o censura del público en vez de seguir apelando a la tradicional aprobación de un monarca, y aquellos que seguían creyendo que los impresos debían promover las buenas costumbres y la obediencia a las autoridades. A ese dilema, muy visible a partir de 1808, se va a agregar luego, hacia 1813, la urgencia de garantizar la unanimidad en la lucha contra un enemigo. Por eso, la libertad de opinión fue en aquel tiempo un precioso dato jurídico al

2 Una caracterización de ese periodo de transición la hace Annick Lemperière, «República y publicidad a finales del Antiguo Régimen (Nueva España)» en Los espacios públicos en Iberoamérica. Ambigüedades y problemas. Siglos XVIII-XIX, eds. François-Xavier Guerra y Annick Lemperière (México: Fondo de Cultura Económica, 1998), 54-79. Más recientemente, para el caso de Nueva España, Gabriel Torres Puga, Opinión pública y censura en Nueva España. Indicios de un silencio imposible, 1767-1794, (México: El Colegio de México, 2010). 
que se podía acudir a la hora de reclamar justicia y respeto a un derecho individual recién conquistado y, con frecuencia, conculcado por gobiernos que todavía ponían en duda la autoridad anónima y general del tribunal de la opinión. El enfrentamiento de esas dos percepciones acerca de la índole que debían tener los impresos fue, por supuesto, el origen de polémicas.

En este ensayo mostraremos el proceso de transformación del espacio público de opinión mediante la instauración de la libertad de imprenta; aunque el proceso pudo contener un cambio genérico en el sistema de comunicación de los individuos y, sobre todo, de deliberación mediante "papeles públicos", es importante destacar los obstáculos, muy particulares, provenientes de situaciones concretas de cada antigua posesión española. Brindar ese paisaje de cambios en varios lugares de la América española es, por supuesto, un ejercicio de historia comparada en que intentamos reconstituir las condiciones de posibilidad para los discursos que le dieron sustento al tránsito a un nuevo sistema político.

\section{Una libertad desigual}

El anuncio de la libertad de imprenta, proveniente de las Cortes de Cádiz en el decreto inaugural del 10 de noviembre de 1810, tuvo desigual acogida en Hispanoamérica; las relaciones de poder, los intereses locales y la presencia o ausencia de autoridades del decaído imperio fueron factores decisivos que limitaron, impidieron o hicieron posible el disfrute de la nueva libertad. El tal decreto fue, en general, el punto de partida de una nueva situación, pero su aplicación concreta en cada lugar de América estuvo sometida a vaivenes que es necesario conocer y explicar.

En Nueva España, hubo apenas fragmentos de disfrute de esa libertad entre 1810 y bien entrado el decenio de 1820. Los funcionarios españoles asentados en ciudad de México impidieron cualquier transición a formas de gobierno constitucional y cualquier asomo de aplicación de principios liberales. El decreto proclamado en Cádiz tuvo una efímera 
aplicación por un virrey que, a regañadientes, y luego de varios reclamos de los delegados mexicanos en España, la admitió. El virrey Venegas la proclamó el 30 de septiembre de 1812 y la suspendió el 5 de diciembre, luego de condenar un artículo publicado por José Joaquín Fernández de Lizardi en su naciente Pensador del 3 de diciembre. Fernández de Lizardi fue a prisión y Carlos María Bustamante, que había sido redactor y director del Diario de México, y que acababa de fundar su Juguetillo, decidió escapar de ciudad de México y unirse al ejército insurgente bajo el mando de José María Morelos ${ }^{3}$. Mientras la prensa oficial centralizada en ciudad de México siguió sometida a la censura previa, algo que ya no sucedía en la península, los periódicos de la insurgencia, a pesar de las limitaciones técnicas, pusieron en práctica la nueva libertad y se convirtieron en medios de comunicación alternativa en las regiones de influencia de los ejércitos de Hidalgo y Morelos. Aún más, la prensa insurgente tomó fuerza como un medio alternativo de difusión de los propósitos de emancipación desde el momento en que el virrey Venegas, según decreto del 19 de enero de 1811, ordenó quemar públicamente cualquier documento proveniente de los insurgentes. Buen testimonio de las precarias condiciones en que emergió la libertad de imprenta en Nueva España fue el periódico Ilustrador Nacional, sucesor del Despertador Americano; su existencia fue resultado de una "imprenta fabricada por nuestras propias manos entre la agitación y estruendo de la guerra"4; su aspecto rústico delata las dificultades en la preparación de cada número. A pesar de su precario funcionamiento, el periódico, como otros que pudieron existir por voluntad de la insurgencia, fue el fugaz pero precioso espacio de la libertad de escribir y publicar que hubo en Nueva España mientras se definía la situación política de aquella colonia.

Fue hasta el reconocimiento de la independencia de Nueva España y el advenimiento al poder de Agustín de

3 Tal evento es evocado por el propio Bustamante en carta a su jefe José María Morelos, donde además se pone a las órdenes del comandante de los ejércitos del sur, en Correo Americano del Sur, Oaxaca, 25 de marzo de 1813, 38.

4 Prospecto del Ilustrador Nacional, Real de Sultepec, 11 de abril de 1812, 1. 
Iturbide que hubo una nueva reglamentación de libertad de imprenta; pero el reglamento quería someter la opinión impresa a los principios de un imperio. Aunque Iturbide y el Ejército Trigarante contaron con el inicial entusiasmo popular y la adhesión de algunas figuras intelectuales importantes, pronto demostró que su gobierno era una mezcla de dictadura militar y monarquía constitucional que deseaba imponer los principios organizativos de un imperio. El reglamento de libertad de imprenta del 13 de diciembre de 1821 acogía la premisa de la abolición de la censura previa y establecía la institución de los jurados de imprenta para juzgar los abusos o excesos cometidos en los impresos; sin embargo, inició el reglamento con una andanada de advertencias acerca de "las bases fundamentales del imperio" que no podían ser transgredidas por sus publicaciones ni los escritores ni los impresores, a riesgo de sufrir años de prisión. El artículo primero expuso todo aquello que no podía ser objeto de ataque o cuestionamiento alguno por medio de impresos. La prensa tenía que aferrarse en ese entonces, según estas exigencias, a los criterios de unanimidad de un gobierno recién instaurado:

\begin{abstract}
Art. 1. Se declaran por bases fundamentales del imperio. Primera: la unidad de la religión católica, apostólica romana, sin tolerancia de otra alguna. Segunda: la independencia de la antigua España, y de otras cualesquiera naciones. Tercera: la estrecha unión de todos los actuales ciudadanos del imperio, o perfecta igualdad de derechos, goces y opiniones, ya hayan nacido en él, o ya del otro lado de los mares. Cuarta: la monarquía hereditaria constitucional moderada, para la que cuidaron de hacer llamamientos el plan de Iguala y tratado de Córdova. Quinta: el gobierno representativo. Sexta: la división de los tres poderes, legislativo, ejecutivo $y$ judicial en los congresos, juntas, personales y tribunales que indica el artículo 14 del tratado de Córdova, y explicará más extensamente la constitución del Imperio ${ }^{5}$.
\end{abstract}

La libertad de imprenta dibujó una parábola diferente en el Río de la Plata. La revolución política propició los decretos

5 Decreto del 13 de diciembre de 1821- Reglamento de libertad de imprenta. Manuel Dublán y José María Lozano, Legislación mexicana o colección completa de las disposiciones legislativas expedidas desde la Independencia de la república, (México: Imprenta del Comercio a cargo de Dublán y Lozano, 1876). 564-567. 
del 20 de abril y 26 de octubre de 1811 . El primero, lo dicen los historiadores argentinos, fue copia textual del promulgado por las Cortes de Cádiz; el segundo refrendó la desaparición de la censura previa ${ }^{6}$. Distinto a México y Nueva Granada, en el Río de la Plata hubo una eclosión de periódicos entre 1815 y 1819; la colección de facsimilares organizada en la Biblioteca de Mayo corrobora ese incremento y deja ver la expansión del periodismo político en esos años ${ }^{7}$. Aun con una legislación en apariencia permisiva, concentrada en controlar y castigar los excesos, los enfrentamientos de facciones políticas condujeron a varios escritores a suspender sus publicaciones, y varias veces les obligó al exilio. El Estado en ciernes pretendió, relativamente temprano, ser el principal regulador del ritmo de la opinión pública impresa, cuando en 1815 fijó un Estatuto Provisional en que anunciaba la creación, bajo su patrocinio, de dos periódicos oficiales con funciones bien diferentes; uno, como censor, y así habría de llamarse, de las ejecutorias de los funcionarios de gobierno; y otro como gaceta oficial encargada de transmitir los actos y pensamientos gubernamentales:

VI-“Se establecerá un periódico encargado a un sujeto de instrucción y talento, pagado por el cabildo, el que en todas las semanas dará al público un pliego o más con el título de Censor. Su objeto principal será reflexionar sobre todos los procedimientos y operaciones injustas de los funcionarios públicos y abusos del país, ilustrando al pueblo en sus derechos y verdaderos intereses."

VII-“Habrá también otro periódico encargado del mismo modo a sujeto de las calidades necesarias, pagado por los fondos del estado, cuyo cargo sea dar todas las semanas una gaceta noticiando al pueblo los sucesos interesantes,

6 Noemí Goldman y Alejandra Pasino, «Opinión pública», en Lenguaje y revolución. Conceptos políticos clave en el Río de la Plata, 1780-1850, ed. Noemí Goldman (Buenos Aires: Prometeo Libros, 2008), 99-113.

7 Nos permitimos la conjetura; en ese lapso pudo haber mayor despliegue de prensa política en el Río de la Plata, sin los obstáculos y privaciones que existieron en la Nueva Granada en plena etapa de reconquista militar española. Tal conjetura no pretende sugerir que en los tiempos de la Primera República haya sido poca la producción y circulación de impresos en Nueva España y Nueva Granada. Pero insistamos, un conjunto legible y accesible de publicaciones periódicas, entre 1815 y 1819, proviene mejor y mayor del legado del Río de la Plata. 
y satisfaciendo a las censuras, discursos o reflexiones del Censor"8.

Concentrados en la discusión acerca del nuevo orden político y sin las aprensiones de la reconquista militar española, la dirigencia criolla pudo deliberar más ampliamente por medios impresos. Desde el decenio de 1810 ya actuaba una Junta Protectora de la Libertad de Imprenta cuya función primordial era contener los abusos de la libertad de imprenta. Muy temprano, el 29 de enero de 1812, hubo la primera comparecencia ante la Junta, le correspondió al número 9 de El Censor, periódico dirigido entonces por Vicente Pazos Silva. El periódico fue absuelto; sin embargo, el gobierno persistió en sus ataques a lo que en ese entonces era la prensa de oposición y obligó al cierre de ese y otros periódicos. A diferencia de las élites de Nueva España, las del Río de la Plata acumulaban, a la entrada del decenio 1820, una mayor tradición de discusión política mediante periódicos con los altibajos inherentes a un ambiente de disputas entre facciones.

En Chile fue acatada la Constitución de Cádiz de 1812 y con base en ella el gobierno de José Miguel Carrera promulgó el reglamento constitucional provisorio del 27 de octubre del mismo año. Pero pronto llegó la pausa restauradora en 1814, cuando la principal imprenta, donde se había impreso la Aurora, quedó en poder español y dio paso a la Gaceta de Gobierno del Rey. Derrotadas las tropas españolas, se restableció la imprenta al servicio de la nueva república; en el ensayo constitucional de 1818 volvió a declararse la libertad de publicar las ideas por medio de la prensa. Luego, la constitución de 1822 (artículo 47), refrendó el propósito de proteger la libertad de imprenta. Una ley del 18 de junio de 1823 tocó por fin un punto conflictivo que había quedado inalterado desde la legislación de 1813, lo concerniente al derecho o no de cuestionar la conducta pública de gobernantes y magistrados; entonces autorizó "la crítica de la conducta ministerial y pública de los magistrados". Poco después, la Constitución

8 El Censor, Buenos Aires, 15 de agosto de 1815, 3-4. En: Biblioteca de Mayo, tomo VIII (Buenos Aires, 1960). 
del 29 de diciembre de 1823 puso el énfasis en la defensa del dogma católico. Sin embargo, la ley casi definitiva fue la promulgada el 6 de diciembre de 1828, vigente en sus líneas gruesas hasta 1925, especialmente en lo tocante a la protección de la iglesia católica como credo oficial del estado chileno. Para Juan Bautista Alberdi, esta ley fue la que organizó de "una manera más extensa el principio constitucional de libertad de pensamiento"; pero como él también lo afirmó, la libertad de imprenta no se asentó en Chile, durante la primera mitad del siglo XIX, por una ley en particular, sino mas bien por una sumatoria de leyes y, por tanto, se volvió asunto "inherente a una forma de gobierno", de modo que cualquier alteración de esa libertad podría entenderse como un trastorno general del sistema de leyes de ese país ${ }^{9}$.

En la Nueva Granada, el constitucionalismo provincial de 1810 a 1815 adoptó, grosso modo, la legislación gaditana sobre libertad de imprenta; sin embargo, a partir de 1813, con la declaración de guerra a muerte contra los españoles proferida por Simón Bolívar hubo, al parecer, el paso a una tensa situación de vigilancia y hasta persecución de algunas publicaciones. Es cierto que la proclama de Bolívar tuvo mucho menos impacto en la Nueva Granada que en Venezuela; aun así, algunos periódicos, a inicios de 1814, alertaron, entre las ciudades de Tunja y Bogotá, acerca de un poder ejecutivo intimidante. Sinforoso Mutis, en su representación que volveremos a citar más adelante, denunció que una proclama que había mandado publicar fue retirada de los lugares de venta y advirtió el contraste entre la constitución política que le garantizaba la libertad de imprimir y las acciones de un poder ejecutivo "para impedir que mi escrito se divulgue en el público"10.

Más claramente, quizás, en la Gaceta de Caracas del 28 de febrero de 1814, el secretario de estado de la república

9 Juan Bautista Alberdi, Legislación de prensa en Chile o sea manual del escritor, del impresor y del jurado (Valparaíso: Imprenta del Mercurio, 1846), 22.

10 «Representación que ha dirigido el ciudadano Sinforoso Mutis al Exmo. Senado», Argos de la Nueva Granada, Tunja-Bogotá, 24 de febrero de 1814, 63. 
confederada de Venezuela les comunicó a los redactores del periódico que habían publicado "avisos oficiales y particulares que han desagradado al Libertador". Por tal motivo, dijo enseguida, Bolívar tuvo la intención de suprimir el periódico y, en vez de eso, resolvió que todo documento oficial podía ser publicado pero con su previa autorización; que sobre los procedimientos de los demás gobiernos no se podían publicar reflexiones "sin consultarlas antes con la Secretaría de Estado, para la previa aprobación del Libertador". Aunque al final del oficio se agregó que estas determinaciones no significaban coartar la libertad de prensa y que era "permitido manifestar [en La Gaceta] las opiniones que quiera", hay que admitir que se trataba de imponer un fuerte control sobre los impresos ${ }^{11}$.

Con el panorama mejor definido, cuando parecía sellado casi del todo el triunfo sobre los ejércitos españoles en el sur de América, la Constitución de Cúcuta, en 1821, legisló en nombre de la nación nueva y triunfante. Podía anunciar y enunciar una estabilidad política plasmada en una república unitaria que reunía a tres antiguas unidades administrativas durante la Colonia y situaba la capital en Bogotá. La ley de libertad de la imprenta data del 17 de septiembre de 1821 y fue publicada íntegramente por la Gaceta de Colombia del 23 de septiembre. No debe interesarnos esa ley solamente, sino el conjunto de leyes relacionadas aprobadas en ese mismo mes; legislación que, en general, puede tomarse como declaración de principios en torno a la libre circulación de las ideas impresas en libros y periódicos. No es baladí que se aprobara, en la misma fecha, una ley acerca de la extinción del Tribunal de la Inquisición en que anunciaba la aparición de una "potestad civil" facultada para juzgar en temas relacionados con "prohibición de libros". También, el 17 de septiembre se aprobó un decreto para asignar un monto de dinero para la adquisición de una "buena imprenta que sirva al Gobierno Supremo de la Nación”. Unos días antes, el 13 de septiembre, fue aprobada una ley sobre exención de portes en los correos a los periódicos y otros impresos, la intención

11 «Oficio del Secretario de Estado a la redacción de la Gaceta», Gaceta de Caracas, 28 de febrero de $1814,2$. 
era facilitar la circulación de "los papeles públicos", y además volvía evidente una relación estrecha entre la circulación de impresos y el sistema de $\operatorname{correos}^{12}$. Una semana después apareció otro decreto que reglamentaba la impresión de la nueva constitución, ningún impresor podía tomar iniciativa para imprimirla o reimprimirla, "todas las ediciones que de ella se hagan serán por orden y cuenta del Gobierno Supremo de la Nación”. Y se añadió otra ley, del 29 de septiembre, que declaraba exentos de derechos de importación a varios artículos, entre ellos

Todos los libros de impresos en cualquier idioma, mapas, cartas geográficas, instrumentos y aparatos filosóficos, grabados, pinturas, estatuas, colecciones de antigüedades, bustos y medallas (...) Las máquinas y aparatos de imprenta, tipos y tinta de imprimir ${ }^{13}$.

Fomentar la instrucción pública y la industria nacional; ilustrar al pueblo; hacer conocer las leyes y hacer respetar las autoridades del nuevo orden hicieron parte de las motivaciones de esta legislación.

En conclusión, la condición política de cada lugar fue determinante; mientras no hubo independencia, no hubo libertad de imprenta. Mientras las autoridades coloniales seguían siendo dominantes, la censura previa prevaleció; ese fue el caso, muy evidente, del virreinato de Nueva España. Entre la crisis monárquica iniciada en 1808 y el retorno de Fernando VII, en 1814, las colonias hispanoamericanas vivieron experiencias muy diferentes en la aclimatación del decreto gaditano que intentaba superar el antiguo sometimiento a la censura previa. En Buenos Aires, en Santiago de Chile, en Caracas y en Santafé de Bogotá florecieron periódicos de inequívocas inclinaciones políticas, concentrados en el examen de la situación inédita del imperio y en la enunciación de las posibles formas de organización política en el porvenir. Y mientras en esos lugares se disfrutaba la novedad de la li-

12 Para leer el compendio de estas y otras leyes emanadas del Congreso de 1821, Cf. Congreso de Cúcuta de 1821. Constitución y leyes (Bogotá: Banco Popular, 1971).

13 Congreso de Cúcuta de 1821. Constitución y leyes, 161. 
bertad de imprenta, en Nueva España el virrey seguía siendo talanquera y garantizó la permanencia de la censura previa. En Nueva España fueron los insurgentes que adoptaron en la práctica, y como desafío a los virreyes, la libertad de opinión y mantuvieron sus propias publicaciones periódicas que fueron, especialmente en la coyuntura de 1810 a 1814 , los voceros de las campañas militares en contra de las tropas españolas.

Lo dicho hasta aquí parece indicar que la libertad de imprenta estuvo escrita desde 1810, pero no fue gozada plenamente desde esa fecha en estricto sentido. Fue una enunciación hecha en Cádiz pero difícil y desigualmente aplicada en Hispanoamérica; mientras permaneciesen las condiciones de subordinación política de las antiguas colonias, esa libertad solo fue una proclama, un decreto que no pudo plasmarse en las situaciones concretas americanas. El caso más notorio es el de Nueva España que tuvo que esperar hasta el decenio de 1820 para afianzar la legislación gaditana de 1810 y darles fijeza a las instituciones encargadas de garantizar la nueva libertad; aun así, el régimen de Iturbide y los siguientes prepararon un terreno de altibajos para la libertad de imprenta. El Río de la Plata ofrece un ejemplo casi opuesto porque hubo un camino expansivo y menos entrecortado de abolición de la censura previa; entre los casos que examinamos es el único que sostuvo un florecimiento de la prensa en la coyuntura de 1814 a 1820, cuando la tentativa de reconquista española y la guerra de liberación consumieron los mayores esfuerzos de las élites locales, lo cual marcó el retardo en el uso sistemático de la prensa como medio permanente de publicación de las ideas. En el Río de la Plata, a diferencia de los otros países que estudiamos, conoció el temprano y controvertido recurso del jurado de imprenta, un mecanismo de control sobre los probables abusos de la libertad de imprenta.

Los contrastes en esta materia hablan de diferencias en la expansión de aquel primer liberalismo proveniente de la legislación gaditana; también indica las diversas gradaciones de la importancia de ciertas posesiones para la Corona española y las diferentes actitudes asumidas por las élites criollas ante la crisis monárquica. Unos prolongaron su lealtad 
más que otros; unos quisieron dar más rápidamente el salto hacia tentativas de organización republicana; unos adoptaron con más rapidez que otros la libertad de opinar como una libertad individual que podía plasmarse cotidianamente en la discusión pública acerca de la encrucijada política y las posibilidades de un nuevo orden. Esos contrastes parecen reunirse en el lapso de 1810 a $1814 \mathrm{y}$, tal parece, solo hasta el decenio de 1820 pueden hallarse vestigios de cierta uniformidad en la adopción reglamentaria de los principios de la libertad de imprenta, aun con altos grados de desconfianza y temor ante la novedosa libertad. En términos generales, fue necesario esperar hasta el decenio 1820 para que se aboliera la censura previa y para que se adoptaran las fórmulas de control basadas, principalmente, en la existencia de jurados de imprenta, institución cuya finalidad más inmediata era evitar los abusos o excesos en el disfrute de la libertad de imprenta.

\section{Libertad de imprenta y modernidad política}

Cuando la libertad de imprenta se anunció y se impuso, con dificultades, en las legislaciones de las incipientes repúblicas hispanoamericanas, ya era asunto discutido en las tradiciones legales de algunos países europeos y en Estados Unidos. Las discusiones habían producido algunos consensos y también dejaban sueltas algunas ambigüedades. No vamos a medir cuál tradición legal tuvo mayor impacto entre la dirigencia criolla latinoamericana, pero tampoco nos arrastraremos por el capricho de volver el asunto un examen unilateral. Digamos, mejor, que los políticos letrados de este lado del Atlántico eran conocedores, así fuese de modo superficial, de lo que en Inglaterra, Francia y Estados Unidos, principalmente, se había dicho durante el siglo XVIII y se seguiría diciendo en los primeros decenios del siglo XIX. Una ausencia es ostensible y explicable, aquella de la tradición alemana, que no es poca; puede haber una razón inmediata, la escasa por no decir nula familiaridad de la dirigencia criolla con esa lengua. Pero basta decir que el país que vio nacer el artefacto de la imprenta tenía que poseer una tradición respetable sobre el significado de la 
libertad de imprenta en aquellos tiempos de cambio político en el mundo ${ }^{14}$.

Varios autores asomaban en las evocaciones de los legisladores y escritores de periódicos americanos; un listado de nombres recurrentes podría suministrarnos un paisaje ideológico del asunto. Dos fuentes o tradiciones nutrieron la discusión que cubrió al principio la península ibérica y las colonias españolas en América. Una provino del pensamiento filosófico y jurídico anglosajón con John Milton a la cabeza; solía recordarse que, en 1643, Milton había alzado la voz contra la censura previa y, además, su nombre era fácil de asociar con la revolución política inglesa. No sabemos si el conocimiento de sus ideas sobre la libertad de prensa provenía de la lectura directa de su Areopagitica (1664) cuyos argumentos a favor de la libre expresión del pensamiento y de las necesarias restricciones en la publicidad estaban relacionados con las conductas al respecto de los gobernantes en la Grecia y Roma antiguas. Otro autor inglés citado como insignia en los comentarios sobre la libertad de imprenta fue William Blackstone; su segundo tomo de los Commentaries on Laws of England (1753) debió interesar por el minucioso inventario que aparece en el capítulo XI del segundo tomo en que describe las actividades asociativas y publicitarias que podrían amenazar lo que él llamaba "paz y buen orden"15.

Pero hubo una fuente común más evidente; tanto la reglamentación gaditana de 1810 como las constituciones elaboradas en las provincias americanas partían de una misma matriz. Al parecer, el liberalismo español y la dirigencia criolla en América bebieron de la fuente común proporcionada por algunos escritos de Jeremías Bentham, transmitidos y comentados por José María Blanco White en su periódico El Español, redactado en Londres. Si se revisa la Gaceta de Caracas (abril de 1811), el Semanario ministerial de Santafe

14 Una visión genérica sobre el caso alemán, en: Jurgen Wilke, "Censorship and Freedom of the Press», in European History Online (EGO), (Mainz: published by the Leibniz Institute of European History (IEG), 2013-05-08).

15 William Blackstone, Commentaries on the Laws of England. Book the first. (Oxford: Printed at the Clarendon Press, 1765), 469- 478. 
de Bogota (julio de 1811) y aun La Bagatela, redactada por Antonio Nariño (diciembre de 1811), será fácil constatar una amplificación de unos primigenios escritos de Bentham sobre la libertad de imprenta en momentos de discusión y debate en la elaboración de las primeras constituciones políticas en Venezuela y Nueva Granada.

Existe una historiografía que durante varios decenios nos ha ilustrado sobre el influjo ejercido por Bentham en las primeras generaciones de políticos republicanos en Hispanoamérica. Intercambios epistolares y legislaciones lo testimonian; pero hay equívocos y excesos en la valoración. No se ha ponderado bien su influencia temprana, aquella anterior al inicio de la década de 1820. Digamos que desde 1978 la historiografía inglesa admite que hacia 1810, o antes, hubo una relación entre Francisco Miranda y el legislador británico que luego se extendió al publicista español residente entonces en Londres, José María Blanco White ${ }^{16}$. Pero el examen matizado de ese encuentro y de la supuesta influencia de Bentham es más reciente. Es cierto, Miranda y Blanco White fueron el puente de transmisión de unos escritos de Bentham sobre la libertad de imprenta que pudieron servir de sustento a los liberales españoles y a la dirigencia criolla, especialmente en Venezuela y Nueva Granada, para redactar las primeras constituciones. Sin embargo, ni la anécdota cierta de la relación temprana con el jurista inglés ni la difusión de sus manuscritos bastan para dar respuesta certera sobre el grado de su influencia. ¿Por qué? Una cosa creía Bentham acerca de la libertad de imprenta, otra cosa necesitaban los legisladores en Hispanoamérica. Bentham, como otros intelectuales británicos, veía entonces con enorme simpatía los sucesos del otro lado del Atlántico; el paso a un régimen de libertades individuales le parecía el más auspicioso. De otra parte, el momento ideológico del jurista inglés era muy particular; se dice que su amistad con James Mill, hacia 1809,

16 Theodora McKennan, "Jeremy Bentham and the Colombian Liberators", The Americas 34, $\mathrm{n}^{\circ} 4$ (1978): 460-475. La autora se basa en un remoto artículo de derecho comparado escrito en 1948 por Kurt Lipstein, «Bentham: Foreign Law and Foreign Lawyers», en Jeremy Bentham and the Law, dirs. George W. Keeton and G. Schwarzenberger, (London: Greenwood, 1948), 202-221. 
había influido fuertemente en su inclinación filosófica radical que le hizo exaltar una democracia liberal en que la libertad de opinión ocupaba un lugar privilegiado ${ }^{17}$.

Un examen, todavía superficial, de las tesis de Bentham y lo plasmado en las constituciones redactadas en Hispanoamérica entre 1810 y 1815, permitiría pensar que "el sabio Bentham" - como ya lo denominaban- no fue seguido al pie de la letra. En principio, los constituyentes criollos pudieron haber compartido las premisas de "asegurar la libertad de imprenta" e "impedir los inconvenientes que esta libertad puede producir" 18 ; también pudieron haber compartido la importancia concedida a la libertad de imprenta como medio de vigilancia de las conductas de los funcionarios públicos. Pero quizás no compartieron el optimismo del pensador inglés en lo concerniente a la confianza que podía depositarse en el pueblo y en la importancia concedida al número, a la mayoría, como fundamento de la discusión pública. La distancia entre los manuscritos del jurista inglés y una realidad inquietante, debieron inclinar a los legisladores hacia una libertad concedida con ambigüedades y temores. Lo cierto es que los artículos sobre libertad de prensa narran, a su manera, tempranas pugnas entre facciones políticas, dificultades para lograr consensos políticos, la necesidad de consolidar a un personal político consagrado a las tareas de representación. La libertad de imprenta tenía que emplearse para "fijar la opinión", para garantizar consensos, para lograr algún nivel de unanimidad y de adhesión en torno a gobiernos incipientes. Además, el manuscrito de Bentham nada dice ante un elemento de ostensible interés para los políticos hispanoamericanos, como lo era la relación con la Iglesia católica. La preocupación por el respeto al dogma católico estaba ausente en su opúsculo, mientras que para las élites criollas y para los liberales españoles era una preocupación inmediata. Los nuevos

17 Un interesante artículo sobre la evolución ideológica de Bentham: J.R. Dinwiddy, «Bentham's Transition to Political Radicalism, 1809-10», Journal of the History of Ideas $36, \mathrm{n}^{\circ} 4$ (1975): 683-700.

18 "Artículo extractado de los manuscritos ingleses de Bentham y publicado por el señor Blanco en su Español», La Bagatela, Santafé de Bogotá, $1^{\circ}$ de diciembre de 1811,86 . 
Estados, según las primeras constituciones políticas, debían ser Estados confesionales, protectores de una religión en particular.

Al lado de la obra de Bentham hay que situar un hecho legislativo inglés de 1792; se trata de la mejor conocida ley de libelos de Fox, donde apareció expuesta claramente la institución del jurado que constituía una salvaguarda ante los probables abusos contra la reputación de las personas y contra los actos de funcionarios de gobierno. Tal ley ofrecía una compensación tranquilizadora a los gobernantes, puesto que al eliminarse la censura previa muchos temían un desborde de la opinión impresa ${ }^{19}$.

Miremos ahora la tradición francesa que, en algunos autores, contuvo algunas conversaciones con la filosofía alemana -algunos citaban a Kant o a Hegel- o con el pensamiento jurídico inglés. No sorprenderá decir que fueron más o menos recurrentes los nombres de Voltaire, Emmanuel-Joseph Sièyes, Joseph-Pierre Chassin, Benjamín Constant y François Guizot. El primero fue frontispicio de muchas reflexiones sobre la libertad de expresión; pero a partir de Sièyes lo que interesaba era la elaboración de un sistema de leyes. El informe que presentó el abate Sièyes ante la Asamblea Nacional en 1790 fue una especie de presagio de lo que los nuevos regímenes políticos debían empezar a domeñar; para él, la libertad de pensar y escribir pertenecían a la órbita del derecho natural, la imprenta no era más que un artefacto que facilitaba el disfrute de ese derecho. Ante la multiplicación de ese artefacto por el mundo y especialmente donde se entronizaban los principios de libertad e igualdad, era indispensable colocar mojones que limitaran esa libertad y, sobre todo, que impidieran excesos perjudiciales para la buena salud de los regímenes republicanos. Las obras de Constant y Guizot, que tuvieron variada audiencia entre la élite

19 Una visión panorámica de la tradición legislativa anglosajona en relación con la difamación y la injuria en la prensa, en Bruce W. Sanford, Libel and Privacy, especialmente el segundo capítulo, (New York: Law and Business, 2004) La edición original de este libro data de 1991. 
hispanoamericana de la post-independencia, contribuyeron sin duda a las reflexiones sobre las posibilidades y restricciones de la libertad de imprenta en el decenio de 1820. El uno y el otro representaron el llamado liberalismo doctrinario que buscaba imponer los lemas de la soberanía de las capacidades y de encauzar institucionalmente el hecho revolucionario; Guizot, mucho más que Constant, ayudó a concebir a la prensa no solamente como un medio de publicidad de la política, sino sobre todo como un lugar privilegiado de definición del poder $^{20}$. Estas muy probables influencias quizás no fueron tan determinantes como obras más puntuales y sistemáticas que contribuían afijar un cuerpo de leyes al respecto, a formar una tradición legal. Nos referimos, por ejemplo, al sistemático Traité des délits et contraventions de la parole, de l'écriture et de la presse, publicado en París entre 1837 y 1839 por JosephPierre Chassan, o los mismos proyectos de ley que discutieron ardorosamente en Francia entre 1814 y $1817^{21}$.

\section{Los significados de la libertad de imprenta}

Políticos y escritores de ambos lados del Atlántico tuvieron una idea exaltada de la libertad de imprenta; era un hecho irrefrenable que correspondía con la instauración de un nuevo sistema político. Las formas de gobierno republicanas necesitaban apoyarse en la libertad de expresar públicamente la opinión mediante impresos. Al lado de eso también se percibía que el mundo de los impresos estaba viviendo una expansión comercial enorme; los talleres de imprenta, las fábricas de papel, los artesanos especializados en el oficio de imprimir estaban multiplicándose por el mundo y, sobre todo en América, hallaban un emergente mercado para libros y periódicos. La libertad de imprenta era un hecho jurídico adherido a un sistema de leyes y un hecho político inherente al sistema republicano e inherente, también, a la expansión del mercado de la opinión. Los alcances de esa expansión podían

20 Pierre Rosanvallon, Democracy Past and Future, (United States of America: Columbia University Press, 2006), 93- 106.

21 Joseph-Pierre Chassin. Traité des délits et contraventions de la parole, de l'écriture et de la presse (París-Colmar: Videcoq-Reiffinger, 1837-1839). 
inquietar a los más libérrimos, entonces se volvió apremiante fijar algunos límites.

Aquí y acullá coincidieron en creer que la médula de la libertad de imprenta era la desaparición de la censura previa. Ahora bien, es necesario hacer una precisión; los periódicos y los textos constitucionales se refirieron mayoritariamente a la libertad de imprenta como una libertad general acerca de la publicación de impresos, entre ellos principalmente los periódicos y los libros. La imprenta era tan solo un medio, el más eficaz como hecho tecnológico, por el cual los individuos podían difundir sus pensamientos, sus opiniones políticas, sus inventos científicos. Es decir, podía haber otros medios de difusión que no solían ser detallados en los enunciados constitucionales. Al referirse de manera genérica a la libertad de imprenta, entendemos que los redactores de las normas estaban hablando, también de forma genérica, de la libertad de opinión, de expresión de esa opinión, que podía ser acelerada o expandida por un elemento tecnológico -la imprenta- cuya eficacia apenas empezaba a percibirse en el caso hispanoamericano.

La libertad de imprenta fue recibida como "fundamento de la libertad civil" y, especialmente, como puerta de ingreso a la modernidad política. Era una libertad que hablaba de hombres que podían conversar públicamente sin aparentes restricciones; aunque era una conversación reducida a los confines letrados, era al fin y al cabo el goce "del primer derecho que tiene todo hombre de hablar, escribir y publicar libremente sus ideas por medio de la prensa", lo decía un periódico bonaerense de $1816^{22}$. Hablar de primer derecho parecía designar la premisa de la discusión política que, en ese entonces, apenas se insinuaba como una disputa permanente fundada en el disenso de las opiniones. La libertad de imprenta, por tanto, anunciaba un mundo de multiplicación de escritores, opiniones e impresos, elementos del nuevo lenguaje político, el lenguaje político de la república, de la reunión de individuos libres capacitados para ejercer la opinión política

22 La Crónica argentina, Buenos Aires, 28 de septiembre de 1816, 67. 
permanente. Treinta años después se había consolidado esta percepción de la libertad de imprenta; Juan Bautista Alberdi, abogado acostumbrado a representar a directores de periódicos en procesos ante tribunales, en fina retrospectiva, concebía la libertad de imprenta como la más preciosa libertad de un individuo, poder publicar lo que pensaba sin la intervención previa de autoridad alguna y dejar al arbitrio de la sociedad el examen de los efectos de esa opinión:

Desde la supresión de la censura -decía Alberdi en 1846es sagrado el secreto del escritor hasta el momento en que emite por la prensa su pensamiento, en cuyo caso solo es responsable a la conciencia del jurado, de las faltas que le hagan culpable a los ojos de la ley (...) La mayor innovación, la única tal vez que la revolución moderna de Ambos mundos haya traído en lo concerniente a la prensa, es la supresión de la censura previa ${ }^{23}$.

Si aceptamos las tesis de Elías José Palti (2005) en su estudio del caso mexicano, es forzoso acoger dos momentos conceptuales tanto para la libertad de imprenta como para la opinión pública en aquel lugar ${ }^{24}$. El momento en que descuella la escritura de José Fernández de Lizardi, El Pensador mexicano, puede entenderse como "transicional"; en sintonía con tal tesis de Palti, agreguemos que Fernández de Lizardi es una figura de transición en la adopción de los principios de la libertad de imprenta porque, quizás bajo el acoso de las circunstancias políticas, prefirió admitir que hablaba como "un buen vasallo". En el número 6 de El Pensador mexicano, año 1813, decidió aludir, con apego literal, a los códigos de comunicación del antiguo régimen:

Yo, a lo menos, he de hacer cuanto estuviere de mi parte,
he de manifestar mis ideas al gobierno y a la nación, que
es en el día mi soberana; he de insistir en avisarla el daño
que la amenaza para que tome las providencias oportunas.
Así lo debo hacer como buen vasallo. Así lo previene la ley
9, partida 2, titular 13, donde dice: Todo buen vasallo debe

23 Alberdi, Legislación de la prensa en Chile, 22-23.

24 Es de nuestra predilección hacer la diferenciación entre una y otra; tomando la libertad de imprenta como premisa político-jurídica que hizo posible el proceso de formación de una opinión pública en las coordenadas del sistema político republicano. 
pensar e conocer aquellas cosas que fueren a pro del rey, para facer que se mantengan, e las que fueren a su daño, para desviarlas, e no tolerarlas, avisando al mismo rey, so pena de ser tenido por mal ome ${ }^{25}$.

En 1821, El Pensador mexicano todavía lanzaba postulados en que evocaba las bondades de formas de comunicación del antiguo régimen; y como individuo atrapado en una transición, mezclaba las innovaciones modernas en legislación sobre la imprenta con los atajos de viejas costumbres que sin pudor aprobaba. Así sucedió cuando propuso, en nombre de la libertad de imprenta, instaurar procedimientos de correspondencia secreta: "uno de los objetos más sagrados a que debe destinarse la libertad de la imprenta -decía- es a ilustrar al gobierno, haciéndole conocer la opinión pública, proponiéndole los medios eficaces para la conservación del buen orden y felicidad de la nación”. En principio, pretendía crear un vínculo directo entre la sociedad y el gobierno, sugerirle un mecanismo de adquisición de información directa de lo que sucedía en la sociedad; a riesgo de acolitar la delación, propuso que se estableciera "una correspondencia secreta entre el público y el gobierno". Enseguida, su justificación tiene algo de pretensión igualitaria, porque se trataba de proporcionarles un medio expedito de comunicación a gentes sin acceso a los canales refinados de la escritura periodística:

Pero como, aunque haya muchos que desean hablar y exponer su sentir en diversas materias, no todos pueden hacerlo: porque unos no tienen estilo, otros no tienen dinero, otros le tienen miedo a don Antonio, y otros carecen de imprentas (porque las pocas que hay suelen estar tan ocupadas que rehúsan los papeles, aun interesantes), se sigue que mil buenas ideas se quedan sofocadas, el gobierno sin una regla cierta para pesar la opinión pública, etcétera, etcétera ${ }^{26}$.

El corolario de su propuesta fue la evocación del uso supuestamente afortunado de tal forma de comunicación en

25 José Joaquín Fernández de Lizardi, «Pensamiento II- Sobre la exaltación de la nación española y abatimiento del antiguo despotismo", en Obras III-Periódicos (México: UNAM, 1968), 66.

26 Fernández de Lizardi, «Pensamiento II», 66. 
los tiempos del virrey-conde Revilla Gigedo, entre 1789 y 1794, momentos de inquietud pública del régimen español por los sucesos revolucionarios de Francia ${ }^{27}$.

En sus vaivenes, El Pensador mexicano saludó el advenimiento de la libertad de imprenta. Fue también en 1821 que hizo una defensa vigorosa de sus implicaciones, "porque, puntualísimamente, ésta es la que lo ha de enseñar a ser libre, y la única fuerza que sostiene y siempre sostendrá la libertad civil del ciudadano"; pero para llegar a esta afirmación había sostenido en varias ocasiones, desde 1812, que no estaba de acuerdo con "la libertad absoluta de imprenta" sino con una "coartada a ciertos límites". Antes de enfrentarse con la curia mexicana por sus veleidades a favor de la masonería, Fernández de Lizardi abogaba por la obediencia al dogma católico y el acatamiento al gobierno: "El discurso es una prenda dada al hombre por la liberalidad del Ser Supremo, y sería una ingratitud execrable hacer del beneficio armas contra el mismo benefactor. Sería igualmente horroroso que abusáramos de esta libertad contra el mismo gobierno que nos la concede"28. Entre sus ires y venires, este escritor mexicano señaló una tendencia, se inclinó por una libertad de imprenta limitada, basada en la desaparición de la censura previa pero, en su remplazo, como veremos luego, compensada por la auto-censura. Aun así, eso no le impidió, en varios momentos, defender su opinión a ultranza o protestar por las restricciones en la circulación de impresos en la capital mexicana o pronunciar frases mucho más afirmativas en favor de la libertad de imprenta cuando la censura multiplicaba sus tentáculos. En una de las conversaciones ficticias y didácticas que supo escribir, El Pensador mexicano, en 1822, recién el gobierno de Iturbide había proclamado el reglamento de libertad de imprenta del 13 de diciembre de 1821, se rebeló ante una libertad que era más letra muerta que vida pública:

27 José Joaquín Fernández de Lizardi, «Correspondencia secreta que a todos van en gallo». En Obras, XI-Folletos (1821-1822). (México: UNAM, 1991), 351-354.

28 José Joaquín Fernández de Lizardi, «Pensamiento I- Sobre la libertad de imprenta», en Obras, III-Periódicos (México: UNAM, 1968), 35-45. 
Don Servilio: Esta maldita libertad ya comienza a declararse contra el trono, como lo ha hecho contra el altar (...) Eso fuera si la libertad de imprenta en México fuera cierta; pero la fortuna es que tiene mil trabas, y a lo menos uno de los fiscales no se descuidará en denunciar cuantos papeles no sean conformes a sus ideas.

A lo que respondió el otro personaje:

Don Liberato: Esa es otra verdad que me tiene desesperado. Cuando reflexiono que tenemos libertad de imprenta con dos fiscales y sesenta jurados que se le pueden venir encima al pobre escritor, por el papel que escribió acaso con las más inocentes intenciones, entonces sí me desanimo y exclamo con usted: ¡maldita sea tal libertad de imprenta! ${ }^{29}$.

Con una frase de Tácito, José María Luis Mora había saludado una nueva etapa de la vida pública: "Época extraordinariamente feliz en que es lícito pensar como se quiera, y decir lo que se piensa"30. Pero fue en 1831 cuando el político mexicano dio una versión más ceñida a la concepción legal que preponderó entre las élites hispanoamericanas; la libertad de imprenta era el fin de la censura previa y, a cambio, estaba controlada en sus eventuales excesos. Entre opinión pública y libertad de imprenta debía existir una coherencia, por no decir armonía. Mientras la opinión pública era fatalmente diversa y su multiplicación podía poner en riesgo el orden político, la libertad de imprenta surgía como un elemento regulador que evitaba la proliferación de opiniones nocivas para la estabilidad del sistema. Los riesgos de sedición o subversión o conspiración podían al menos detectarse en la cotidiana vigilancia de los impresos; el ejercicio oficial de esa vigilancia hacía parte, según el escritor político, de la libertad de imprenta como dispositivo regulador de la circulación de la opinión:

29 José Joaquín Fernández de Lizardi, «Maldita sea la libertad de imprenta. Diálogo entre don Liberato y don Servilio», en Obras, XI-Folletos (1821-1822), (México: UNAM, 1991), 501-512.

30 José María Luis Mora, «Discurso sobre la libertad de pensar, hablar y escribir», El Observador de la República mexicana, México, 13 de junio de 1827, 24. 
P-¿Qué cosa es la libertad de imprenta?

R- El derecho de exponer al público por medio de la prensa sus propias ideas sin necesidad de aprobación ni previa censura, aunque con la obligación de responder a la autoridad pública del abuso que de su ejercicio pueda hacerse.

P- ¿La libertad de imprenta es la misma o distinta de la de pensar?

R- Es la misma libertad de pensar fundada en un principio de eterna justicia, a saber: que los actos del entendimiento como necesarios por su esencia y considerados en el orden metafísico no son susceptibles de moralidad, no pueden contarse entre los crímenes ni delitos, y es de justicia que sean libres en el orden político (...)

P- ¿Pues no es un medio de fomentar la sedición la libertad de imprenta y no la ha producido muchas veces?

R- No, por el contrario, cuando a los hombres se les permite quejarse de lo que real o aprendidamente sufren, lo regular es que se contenten con esto; mas si la autoridad se los impide, entonces se irritan de que no pueda sufrir una censura que necesariamente le impone freno porque saca a plaza sus desaciertos o maldades, y en este caso es en el que traman las conspiraciones y se proyecta seriamente derribarla: así es claro que no el ejercicio de la libertad de imprenta, sino el abuso de la autoridad es lo que provoca la sedición. Además con la libertad de imprenta el gobierno no solo tiene un medio infalible de ilustrarse en la opinión del público que jamás debe ignorar ni seguir muy de lejos, sino también un conducto seguro para saber lo que se trama contra el orden público en tiempos revueltos, pues rarísima vez deja de traslucirse algo por los papeles públicos; y un gobierno que sabe o sospecha la existencia o principio de una conspiración, tiene mucho adelantado para impedirla o sofocarla ${ }^{31}$.

Los escritores chilenos, argentinos, neogranadinos, mexicanos participaron del entusiasmo por la adquisición de una libertad individual que permitía zafarse de la censura previa; y todos adoptaron esta libertad unida a una necesaria censura a posteriori. La regulación de esa libertad era una

31 José María Luis Mora, Catecismo político de la federación mexicana (México: Imprenta de Galván, 1831), 554. 
precaución necesaria para evitar el desborde de opiniones que podía terminar por aniquilar las bases de legitimidad del nuevo orden político; la estabilidad de ese nuevo orden debía proceder de una regulación de la opinión. La libertad de imprenta era una realización de un principio liberal, pero ceñida a las márgenes de una cautelosa élite política. Pero a medida que se aclimató la nueva libertad surgieron los obstáculos más conspicuos; de un lado, los posibles excesos de los escritores y, de otro, las posibles arbitrariedades de las autoridades celosas en "la protección" o vigilancia de la libertad de imprenta. Las opiniones particulares difuminadas en el espacio público necesitaban una regulación estatal mediante reglamentos, tribunales y juntas de la libertad de imprenta. En el Río de la Plata, donde cualquier exceso de la opinión quedaba sometido a condenas ejemplarizantes -el destierro en la Patagonia era uno de los castigos predilectos a los escritores libérrimos- el riesgo de la tiranía censora quedó en evidencia. Ese riesgo lo corrían, principalmente, quienes preferían asumir sus propias aventuras editoriales, lejos de la opinión oficial sostenida por los redactores de gacetas ministeriales. Cuando Bernardo de Monteagudo, que había sido redactor de la Gaceta de Buenos Ayres, decidió fundar su propio periódico, sabía que se separaba de una situación segura y comenzaba a asumir los riesgos de cualquier individuo que quería sostener su opinión particular en medio de una incipiente libertad de imprenta:

Persuadido de estas máximas me creo en la obligación de sostener un nuevo periódico, que sirva de asilo a la LIBERTAD, continuando en él las materias que seguía en la Gazeta: de este modo el que quiera publicar sus sentimientos tendrá un recurso para hacerlo, y yo estaré siempre alerta para apoyar o impugnar las opiniones ministeriales, aunque cargue sobre mí la execración de los tiranos y el escándalo de los esclavos ${ }^{32}$.

La nueva libertad tuvo una limitación ostensible; la censura previa persistió en los temas religiosos. La Iglesia católica conservaba la potestad de examinar todo aquello

32 Mártir o Libre, Buenos Aires, 29 de marzo de 1812, 1-2. 
que pudiese atentar contra su dogma. Las antiguas colonias españolas en América proclamaron, en sus primeras tentativas constitucionales, su apego a la religión católica y eso tuvo expresión en la reglamentación de la libertad de imprenta. Las constituciones provinciales de la Primera república, en la Nueva Granada, mezclaron las posibilidades deliberativas de la nueva libertad con las advertencias acerca del respeto al dogma católico. En la Constitución de la provincia de Mariquita, por ejemplo, se pretendió conferirle a la libertad de opinión la capacidad de intervención, de examen y vigilancia sobre la representación política y los funcionarios del gobierno, algo que había sido materia de discusión en Francia en los años inmediatamente posteriores de su revolución, y al lado se agregaba el respeto al dogma católico:

La libertad de imprenta es esencialmente necesaria para sostener la libertad del Estado. Por medio de ella puede todo ciudadano examinar los procedimientos del Gobierno en cualquier ramo, la conducta de los funcionarios del pueblo como tales, y hablar, escribir, reimprimir libremente lo que guste, exceptuándose los escritos obscenos y los que ofendan al dogma, quedando responsable del abuso que haga de esta libertad en los casos fijados por la ley ${ }^{33}$.

La Constitución del Estado de Antioquia de 1812 es más generosa en contradicciones y nos permite sospechar un ambiente político repleto de tensiones, es la que mejor condensa las aprensiones del personal político-letrado de la época. Como otras, comenzó anunciando que la libertad de imprenta "es el más firme apoyo de un Gobierno sabio y liberal"; al parecer, el deseo más inmediato de los gobiernos provisorios de aquel tiempo fue encontrar en los impresos un medio de difusión de la actividad de los nuevos gobernantes y, por tanto, un recurso rápido y eficaz de legitimación. Enseguida, hay un artículo, como en casi todas las legislaciones de la época, consagrado a advertir que "no se permitirán escritos que sean directamente contra el dogma y las buenas costumbres". La

33 Constitución de Mariquita, 21 de junio de 1815, Título I, artículo 9, p. 647. Sobre la semejanza con la libertad de opinión como ejercicio del poder de vigilancia o de ratificación de los actos legislativos, Pierre Rosanvallon, La démocratie inachevée (París: Gallimard, 2000), 44-46. 
defensa del dogma católico, se entiende, siempre estuvo en correspondencia con declarar a esa religión como la oficial del Estado. Pero, he aquí lo que más nos interesa por ahora, sigue otro artículo que dice: "Tampoco se permitirá ningún escrito o discurso público dirigido a perturbar el orden y la tranquilidad común, o en que se combatan las bases de gobierno adoptadas por la provincia, cuales son la soberanía del pueblo y el derecho que tiene y ha tenido para darse la Constitución que más le convenga". La impresión y puesta en circulación de escritos que pudieran cuestionar las bases de un gobierno, su legitimidad, todo aquello que no contribuyera a la urgencia de un consenso podría ser considerado como "un crimen de lesa patria" ${ }^{34}$.

El aspecto religioso católico fue un elemento perturbador de la libertad de imprenta y contribuyó a percibirla como un logro incompleto; el derecho de tener opinión sobre cualquier asunto, incluía, para algunos, referirse sin trabas a lo religioso. Hacia 1816, en Buenos Aires, La Crónica argentina estimaba que un periódico semi-oficial, El Censor, estaba dedicado a organizar la persecución contra todos aquellos que dijesen algo contra la iglesia católica ${ }^{35}$. En México, mientras tanto, Fernández de Lizardi tuvo varios enfrentamientos con miembros del clero que lo acusaban de agitar temas exclusivos de los guardianes de ese credo ${ }^{36}$. Ese fue, quizás, el aspecto más restrictivo y prolongado en las vidas públicas de los países hispanoamericanos. La libertad de imprenta vivió de impulsos y estuvo sometida a momentos de arbitrariedad y fuertes restricciones. En general, luego de las reglamentaciones casi pioneras de la década 1820, vinieron controles estrictos del Estado sumados al sometimiento a la vigilancia eclesiástica. Salvo lo sucedido en la Nueva Granada, con el advenimiento de las reformas liberales de mitad de siglo, los demás países aquí estudiados padecieron restricciones y controles en la libertad

34 Constitución del Estado de Antioquia, 21 de marzo de 1812, Sección II, art. $3^{\circ}$, p. 466. No hay ostensibles cambios en la Constitución del 10 de julio de 1815, también del Estado de Antioquia.

35 Crónica argentina, Buenos Aires, 30 de septiembre de 1816, 71-77.

36 José Joaquín Fernández de Lizardi, «Papeles contra sermones», en Obras, XIFolletos (1821-1822), (México: UNAM, 1991), 61-75. 
de imprenta. La Nueva Granada tuvo desde 1851 hasta 1887 una libertad absoluta de imprenta, sin el sistema de jurados y sin censura eclesiástica previa. Chile, Argentina y México afirmaron estrictos y hasta arbitrarios controles estatales y le concedieron lugar preponderante a la Iglesia católica en la vigilancia de la opinión impresa ${ }^{37}$.

La libertad de imprenta terminó siendo un universo de opinión cercado por restricciones que moldearon la esfera pública. Hubo cierta sofisticación del universo censorio que brindó terreno movedizo a la producción y circulación de impresos. Fijémonos en algunos casos de censura y de limitaciones en la libertad de opinión que ayudan a entender lo inquietante que fue, para las élites de los primeros decenios republicanos, la producción y circulación de ideas por medio de "papeles públicos".

\section{Censuras y restricciones en el nuevo orden}

Hubo variados atascos contra la libertad imprenta. Mencionemos y tratemos los más evidentes y mejor documentados: los amagos de retorno a la censura previa, aparte de la casi inconmovible censura eclesiástica previa; los estorbos a la circulación de impresos, muchas veces cubierto de parafernalia legal; las restricciones provenientes de los juicios de imprenta.

La Constitución de Cádiz de 1812 enunciaba de modo afirmativola abolición dela censura previay, en principio, esafue la gran novedad y la esencia de la nueva libertad; los escritores, en Hispanoamérica, podían en adelante escribir y publicar sin la necesidad de una "superior licencia". Tradicionalmente, entre escribir y publicar estaba situada la autoridad del rey que permitía, o no, pasar de una a otra situación. Ahora se podía escribir, publicar y luego, de ser necesario, se respondía ante las autoridades por cualquier exceso en el disfrute de

37 Sin olvidar que el decreto gaditano de 1810 inauguró esta legislación a favor de la censura previa eclesiástica y admitió la presencia del clero en las juntas de censura; tremendo legado de este primer y tímido liberalismo. 
la libertad. Pero la abolición de la censura previa no llegó a las colonias americanas tan fácilmente; hubo resistencias, simulaciones, temores, incluso amagos de aplicación de la censura a priori, así fuese por la iniciativa muy marginal de algunos particulares. Asoma un ejemplo leyendo El Censor de Buenos Aires, en pleno 1812, cuando ya conocían los letrados americanos el decreto inaugural gaditano de 1810. Ya no era el rey español y sus autoridades delegadas en América las que podían ejercer la censura previa sobre los escritos; las nuevas asociaciones letradas, nacidas como expansión del mundo de la opinión, recibían la facultad censora. En el periódico mencionado, la Sociedad Patriótico-Literaria anunciaba que los discursos o memorias de miembros de esa asociación que se diesen a la prensa, debían ser objeto de censura previa y llevar "nota de aprobación de los censores"; si no era así, no podían presentarse como propios de la Sociedad ${ }^{38}$. La medida no duró mucho, es cierto; pocos meses después apareció otro anuncio de la misma asociación en que decía:

(La Sociedad Patriótico-Literaria) continúa sus sesiones en la forma anunciada, y todos los ciudadanos que quieran concurrir con sus conocimientos podrán hacerlo, en inteligencia que la previa censura que se exigía antes de publicar las memorias, se ha derogado en favor de la libertad que concede la ley a todo el que no abusa de ella ${ }^{39}$.

Aquel breve ejercicio censor, y auto-censor, no estaba extendido a todos los escritores, sino a aquellos vinculados con esa asociación. De modo que se trataba de algo fragmentario; sin embargo, alcanza a delatar la permanencia de un espíritu temeroso ante la amplitud que pudiese tomar la nueva libertad. Ese ejercicio de censura previa -que quizás no pasó de ser una tentativa- circunscrito a un conjunto de individuos letrados reunidos en una asociación era compatible con el funcionamiento, en Buenos Aires, de la Junta Protectora de la Libertad de Imprenta.

38 El Censor, Buenos Aires, 28 de enero de 1812, 16.

39 Mártir o Libre, Buenos Aires, 20 de abril de 1812, 32. 
Hacia 1814, en Nueva Granada y Venezuela, la censura previa quiso imponerse oficialmente en las huestes bolivarianas, cuando ya se habían acumulado suficientes enfrentamientos entre realistas y patriotas, entre federalistas y centralistas. Entre enero y agosto de 1812, el Estado de Cundinamarca, al mando de Antonio Nariño, les declaró la guerra a las Provincias Unidas; mientras tanto, en Venezuela, el 4 de abril de 1812, se le otorgó facultades extraordinarias al Ejecutivo. El 15 de junio de 1813, Simón Bolívar declaró la guerra a muerte a los españoles. En un momento álgido de alinderamientos políticos y militares, de concentración del poder en un individuo -para entonces el Libertador ya era, también, un dictador que reunía las facultades de los tres poderes- la libertad de imprenta consagrada en las primeras constituciones quedó sometida al arbitrio de un férreo poder ejecutivo concentrado en la dirección de la guerra ${ }^{40}$. Como lo hemos dicho en página anterior, Simón Bolívar llegó a tener la intención de clausurar la Gaceta de Caracas en febrero de 1814, y optó finalmente por ejercer censura previa.

Para comienzos de 1814, cuando ya había retornado el rey Fernando VII al trono en España, en territorio neogranadino hubo serios amagos reaccionarios. El Argos de la Nueva Granada contiene testimonios de debates en torno a una nueva legislación que contribuía al retorno de la Inquisición o, al menos, a los tiempos de la censura eclesiástica previa sobre cualquier impreso; además se denunciaba la represión de las autoridades que ordenaban confiscar algunos impresos puestos en circulación. Las denuncias y argumentos difundidos en el periódico del 24 de febrero de 1814 no solo hablaban de una legislación que pretendía imponer de nuevo el lenguaje de los anatemas contra supuestos herejes, sino que coartaba las conquistas recién adquiridas por el espíritu liberal de entonces; se denunciaba, además, que no se convocara regularmente a elecciones. Por eso, una de las denuncias presentadas por quien se presentaba como un suscriptor del periódico en mientes, remataba así:

40 Sobre ese momento político, tanto en la Nueva Granada como en Venezuela, Cf. Clément Thibaud, Repúblicas en armas (Bogotá: Planeta, 2003), 140-148. 
A Dios mi amigo, no vengas por acá hasta que esté restablecida la constitución; que reine la ley y no la voluntad caprichosa de los hombres: que haya libertad de imprenta, que se respeten los derechos del hombre; que haya elecciones periódicas sin interrupción, que los Ciudadanos puedan libremente hablar y escribir, y en fin que no haya Dones ni Cruzados, sino Ciudadanos en todo iguales delante de la ley ${ }^{41}$.

La denuncia evocaba que hacia fines de 1813 fueron aprobadas por el Congreso del Estado de Cundinamarca algunas leyes que restablecían para la Iglesia católica potestades en torno a la delación, persecución e incluso condena de aquellos individuos que atentaran con sus opiniones contra la preeminencia del dogma católico; además, el Poder Ejecutivo había dispuesto suspender la convocatoria del Colegio Electoral $^{42}$. En fin, el peligro de que el Gobierno mutara de "popular representativo" a "monárquico u oligárquico" -como lo decía el anónimo suscriptor- que hubiese un probable retorno o triunfo de los partidarios de una regencia y que se consolidara un definido partido a favor de una causa patriótica, todo eso volvía inexorable la apelación a lo que él llamaba el "Tribunal de la opinión pública". Este "Tribunal de la opinión pública" era el último y supremo recurso para lograr el triunfo de la razón, por su carácter "incorruptible e imparcial".

José María Luis Mora, en las primeras páginas de $E l$ Observador de la República mexicana de 1827, saludaba la libertad de imprenta y deseaba que todos los impresos estuviesen "libres de toda censura que preceda o siga a su publicación" ${ }^{43}$. Ambas cosas se habían obtenido hasta entonces muy relativamente; conocedor de la experiencia periodística en su país, Mora se refería, sin duda, a los métodos de evitar

41 «Noticias del interior», Argos de la Nueva Granada, Tunja-Bogotá, 24 de febrero de 1814, 63.

42 El denunciante cita, por ejemplo, en materia de opiniones sobre la religión católica, el acuerdo del 30 de octubre de 1813, publicado en Gaceta ministerial del 11 de noviembre; y el decreto del 7 de diciembre del mismo año, publicado en Gaceta ministerial del 16 del mismo mes, sobre suspensión de la convocatoria del Colegio Electoral.

43 El Observador de la República mexicana, México, 13 de junio de 1827, 24. 
la circulación de impresos. La documentación de aquellos primeros decenios republicanos habla de libertades coartadas, es cierto, pero también revela una intensa esfera pública en que intervenían muchos agentes que permitían el contacto cotidiano de la cultura letrada con el variopinto universo de las tradiciones orales. Los voceadores de prensa en las calles propiciaban ese diálogo; el solo grito de una noticia, de un epígrafe o hasta la mención de un nuevo periódico animaban la curiosidad callejera, preparaban el corrillo, la lectura en voz alta, el chismorreo y, claro, hasta la venta más o menos profusa de ejemplares de algún impreso. El Pensador Mexicano y otros publicistas de aquellos primeros decenios del siglo XIX conocieron el saboteo, entre autorizado y solapado, de las publicaciones que deambulaban por las calles en manos de voceadores o colocadas en portales de librerías. En varias ocasiones, los gobernantes mexicanos prohibieron el grito de los voceadores, especialmente en ciudad de México; la medida buscaba, en apariencia, evitar algarabías en las calles y, peor, la incitación a motines o conspiraciones. Ante esas prohibiciones, Fernández de Lizardi optó por hablar así, en 1821, mientras estaba en la cárcel, acerca de la necesaria publicidad para sus impresos:

\begin{abstract}
Como este superior gobierno tiene prohibido que se vendan los impresos a los revendedores, porque estos incomodan al público con sus gritos, es necesario advertir que este papel y cuantos diere a luz se hallarán en el Portal, en todos los puestos públicos, así porque me interesa que se vendan, como porque la ley me permite publicar mis ideas políticas (Constitución, artículo 371), y para el caso, tanto me importa que los griten los muchachos, como que sepa el público dónde se expenden mis impresos ${ }^{44}$.
\end{abstract}

El mismo escritor sabía de los efectos posibles del decomiso de algún escrito ya colgado en los lugares de distribución callejeros y sostenía que el procedimiento era ineficaz para evitar la circulación de un impreso censurado. Lo más probable es que provocara lo contrario:

44 Observaciones político-legales que en abono de sus impresos hace el Pensador Mexicano (México: Imprenta de Mariano Ontiveros, 1821), 159-173. 
Fuera de que el medio de recoger un papel será muy bueno, pero nunca llenará el deseo de la ley, que es impedir su circulación. La razón es clara. Se imprimen mil ejemplares y se recogen diez, ¿qué aprovecha? Pregúntese cuántos ejemplares se imprimieron de Las verdades amargan, de las Zorras y otros recogidos, y luego cotéjese el número de éstos con el de aquellos y se verá una desproporción, acaso de uno a ciento ${ }^{45}$.

Volviendo a la Nueva Granada, Sinforoso Mutis -sobrino del director de la Expedición Botánica, compañero de Antonio Nariño en la campaña militar de 1812- en la representación que envió al Senado el 16 de febrero de 1814 alertaba sobre un momento penumbroso para la libertad de imprenta; acudió a un epígrafe aleccionador, citó una frase seguramente proveniente de los manuscritos de Bentham publicados en uno de los primeros números de El Español: "La libertad de la imprenta no depende de la censura anterior o posterior, sino de la libre circulación de los escritos"46. El epígrafe anunciaba bien la índole del reclamo que expuso Mutis; por orden del Poder Ejecutivo, un alguacil recogió 131 ejemplares de un impreso de su autoría que había puesto a la venta en una tienda. Es interesante ver cómo el autor de la representación y del impreso acude a la Constitución política para demostrar que varios derechos le habían sido vulnerados y que había, por tanto, un abismo entre los derechos consagrados y los actos del Poder Ejecutivo. Con la confiscación del impreso puesto ya en venta, Mutis pensaba que le estaban conculcando varias libertades conexas: la de impresión, la de circulación de impresos, la de disponer de sus bienes y rentas, la de gozar y disponer del fruto de su ingenio. En definitiva, una gama de libertades que circulaban desde la difusión de los derechos del hombre y el ciudadano y que fueron también proclamadas en casi todas las constituciones del interregno de 1811-1815.

45 José Joaquín Fernández de Lizardi, Obras (1821-1822), (UNAM, 1991). «Quien mal pleito tiene, a voces lo mete» (México: Oficina de J.M. Benavente, 1821), 39.

46 «Representación que ha dirigido», 63. 


\section{Conclusiones}

Los ejemplos pueden multiplicarse, pero bastan estos para hacernos a una idea de un ambiente muchas veces hostil para una libertad individual más enunciada que aplicada. En estos primeros decenios de ambigüedades republicanas fue esbozándose una historia menuda de avances y retrocesos en materia de difusión de impresos que hace falta documentar. Hasta ahora podemos hablar de un momento indeciso, en que hubo un forcejeo entre aquellos que abogaban por la instauración de principios liberales y unos gobiernos que temían, con o sin fundamento, un desbordamiento del ejercicio pleno de ciertas libertades individuales. La institución del jurado de imprenta motivó frecuentes discusiones sobre los alcances y límites de la libertad de la prensa y, al tiempo, moldeó el carácter de la opinión pública. Unos lo vieron como garantía de salvaguarda de honras y dignidades atropelladas por cualquier papel público; otros lo encontraron funesto para el despliegue de la libertad de pensamiento.

La relación entre una legislación nueva sobre libertad de imprenta y las condiciones de funcionamiento de un régimen político fue inmediata y ayuda a entender las diferencias en su aplicación en el subcontinente americano. Aquellos lugares donde la dominación española y el predominio de una estructura jerárquica seguía vigente en los primeros decenios del siglo XIX, hizo muy difícil la ampliación del espacio público de opinión. De todos modos, en términos generales, la nueva libertad fue acogida y, a la vez, temida. Su aplicación estuvo mediada por una legislación que quiso evitar desbordes; para eso fue útil acudir a modelos de interpretativos y legislativos provenientes de países que acumulaban mayor experiencia en la puesta en práctica de esa libertad. Sin duda, la apelación a un tribunal o jurado fue la principal novedad en un régimen de libertad de imprenta sin censura previa y su aplicación debió ser otro aliciente de la discusión cotidiana. Ese asunto, la institución del jurado de imprenta merece tratamiento aparte. 


\section{Fuentes documentales}

"Artículo extractado de los manuscritos ingleses de Bentham y publicado por el señor Blanco en su Español», La Bagatela, Santafé de Bogotá, $1^{\circ}$ de diciembre de 1811.

«Noticias del interior», Argos de la Nueva Granada, Tunja-Bogotá, 24 de febrero de 1814.

Correo Americano del Sur, Oaxaca, 25 de marzo de 1813.

Constitución de Mariquita, 1815.

Constitución del Estado de Antioquia, 1812.

El Censor, Buenos Aires, 15 de agosto de 1815.

El Censor, Buenos Aires, 28 de enero de 1812.

El Observador de la República mexicana, México, 13 de junio de 1827.

Gaceta de Caracas, Caracas, 28 de febrero de 1814.

Gaceta ministerial, Santafé de Bogotá, 1813.

La Crónica argentina, Buenos Aires, 28 de septiembre de 1816. , Buenos Aires, 30 de septiembre de 1816.

Mártir o Libre, Buenos Aires, 20 de abril de 1812.

Mártir o Libre, Buenos Aires, 29 de marzo de 1812.

Prospecto del Ilustrador Nacional, Real de Sultepec, 11 de abril de 1812.

«Representación que ha dirigido el ciudadano Sinforoso Mutis al Exmo. Senado", Argos de la Nueva Granada, Tunja-Bogotá, 24 de febrero de 1814. 


\section{Bibliografía}

Alberdi, Juan Bautista. Legislación de prensa en Chile o sea manual del escritor, del impresor y del jurado. Valparaíso: Imprenta del Mercurio, 1846.

Blackstone, William. Commentaries on the Laws of England. Book the first. Oxford: Printed at the Clarendon Press, 1765

Chassin, Joseph-Pierre. Traité des délits et contraventions de la parole, de l'écriture et de la presse. París-Colmar: VidecoqReiffinger, 1837-1839.

Congreso de Cúcuta de 1821. Constitución y leyes. Bogotá: Banco Popular, 1971.

Dinwiddy, J.R. «Bentham's Transition to Political Radicalism, 180910». Journal of the History of Ideas 36, nº 4 (1975): 683-700.

Dublán, Manuel y José María Lozano. Legislación mexicana o colección completa de las disposiciones legislativas expedidas desde la Independencia de la república. México: Imprenta del Comercio a cargo de Dublán y Lozano, 1876.

Fernández de Lizardi, José Joaquín. «Correspondencia secreta que a todos van en gallo». En Obras, XI-Folletos (1821-1822). México: UNAM, 1991, 351-354.

. «Maldita sea la libertad de imprenta. Diálogo entre don Liberato y don Servilio. En Obras, XI-Folletos (18211822). México: UNAM, 1991.

. "Papeles contra sermones», en Obras, XIFolletos (1821-1822), México: UNAM, 1991.

. «Pensamiento I- Sobre la libertad de imprenta». En: Obras III-Periódicos. México: UNAM, 1968.

. «Pensamiento II- Sobre la exaltación de la nación española y abatimiento del antiguo despotismo». En: Obras III-Periódicos. México: UNAM, 1968. 
Goldman, Noemí y Alejandra Pasino. "Opinión pública». En Lenguaje y revolución. Conceptos políticos clave en el Río de la Plata, 1780-1850, editado por Noemí Goldman. Buenos Aires: Prometeo Libros, 2008.

Lemperière, Annick. «República y publicidad a finales del Antiguo Régimen (Nueva España)». En Los espacios públicos en Iberoamérica. Ambigüedades y problemas. Siglos XVIII-XIX, editado por François-Xavier Guerra y Annick Lemperière. México: Fondo de Cultura Económica, 1998.

Lipstein, Kurt. «Bentham: Foreign Law and Foreign Lawyers». En Jeremy Bentham and the Law, dirigido por George Keeton y G. Schwarzenberger. London: Greenwood, 1948.

Mora, José María Luis. «Discurso sobre la libertad de pensar, hablar y escribir», El Observador de la República mexicana, 13 de junio de 1827.

Catecismo político de la federación mexicana. México: Imprenta de Galván, 1831.

McKennan, Theodora. «Jeremy Bentham and the Colombian Liberators». The Americas 34, n 4 (1978): 460-475.

Observaciones político-legales que en abono de sus impresos hace el Pensador Mexicano. México: Imprenta de Mariano Ontiveros, 1821.

Rosanvallon, Pierre. Democracy Past and Future. United States of America: Columbia University Press, 2006.

2000.

La démocratie inachevée. París: Gallimard,

Sanford, Bruce. Libel and Privacy. New York: Law and Business, 2004.

Thibaud, Clément. Repúblicas en armas. Bogotá: Planeta, 2003.

Torres Puga, Gabriel. Opinión pública y censura en Nueva España. Indicios de un silencio imposible, 1767-1794, México: El Colegio de México, 2010. 
Wilke, Jurgen. "Censorship and Freedom of the Press». In: European History Online (EGO). Mainz: published by the Leibniz Institute of European History (IEG), 2013-05-08.

\section{Citar este artículo:}

Loaiza Cano, Gilberto. «La libertad de imprenta en la América española (ensayo de historia comparada sobre la opinión pública moderna)». Historia Y MEMORIA, n 13 (2016): 4784. DOI: http://dx.doi.org/10.19053/20275137.5200 